\title{
Scientometric Analysis of Dynamics of the Number of Publications on Environmental Issues
}

\author{
Angelika V. Salagaeva ${ }^{\mathrm{a}, \mathrm{b} *}$, Sergey V. Tazeev ${ }^{\mathrm{a}, \mathrm{b}}$, \\ Vladimir L. Gavrikov ${ }^{\mathrm{a}}$ and Rem G. Khlebopros ${ }^{\mathrm{a}, \mathrm{b}}$ \\ ${ }^{a}$ Siberian Federal University \\ 79 Svobodny, Krasnoyarsk, 660041, Russia \\ ${ }^{b}$ Presidium of Krasnoyarsk Research Centre of SB RAS \\ 50 Akademgorodok, Krasnoyarsk, 660036, Russia
}

Received 27.04.2016, received in revised form 07.07.2016, accepted 26.07.2016

In this article scientometric analysis of the data on the number of publications on six environmental issues is conducted. The following methods of analysis were applied: the method of linear interpolation, ssa method and correlation analysis.

An analytical expression to describe the changes in the number of publications over time was found by the method of linear interpolation. The degree of the data "pollution" was analyzed by SSA method. The rate of change in the number of publications in a given time interval is analyzed in details. The substantial significance of external factors on the initial number and dynamics of the publications growth is shown.

Keywords: Kyoto forests, dynamics of publications, Verhulst equation, SSA method.

DOI: 10.17516/1997-1370-2016-9-8-1710-1718.

Research area: economics.

\section{Introduction}

Global environmental problems, that are the problems concerning the entire biosphere of the Earth, are one of the most pressing ones. Our civilization must be a part of the Earth's ecosystem. Climate research has become a priority area, numerous committees are created and allocated funds are increasing [1].

Since the end of the last ice age (about 10 000 years ago) up to 1750 the content of $\mathrm{CO}_{2}$ in the atmosphere had been almost unchanged, and after the start of the Industrial Revolution it started to grow exponentially. It is possible to compare this growth with another exponent an increase in carbon fuel consumption, which for the recent time has been doubling every ten years. Exponential growth is very rare in nature: it means a positive feedback when an increase of a factor leads only to its further growth and inhibiting factors do not function. This happens

(C) Siberian Federal University. All rights reserved

* Corresponding author E-mail address: angelika_80_75@mail.ru 
during various disasters such as forest fires and avalanches. On the contrary, in human activity positive feedback occurs very often. There is no doubt that both exponential processes - the growth of carbon fuels consumption and the growth of carbon dioxide content are connected, and that the first is the cause of the second one.

Technical human activity, and especially energetics based on fossil fuel combustion, changes the composition of the Earth's atmosphere. The rate of anthropogenic residues production is 2 orders of magnitude more than the rate of natural carbon geochemical cycle capable to dispose of these residues. This change inevitably leads to climate change, which has already been observed and can be predicted for the future. The escalation of the global warming effect [2] may lead to an increase in average global temperature of the planet by $1^{\circ}$ C. $60 \%$ of the greenhouse effect is caused by carbon dioxide. The urgency of the necessary measures is connected with the fact that $\mathrm{CO}_{2}$ and other "greenhouse gases", once in the atmosphere, can remain there at least for hundreds of years. The greatest increase in temperature will happen between $40^{\circ}$ and $70^{\circ}$ $N$ [3]. It was exactly in these places where the greatest warming occurred in the $20^{\text {th }}$ century. For example, at the current level of carbon fuels consumption, the average temperature in July in the centre of Washington is now $30^{\circ} \mathrm{C}$, and in a hundred years it will increase by $5^{\circ} \mathrm{C}$ [4]. To change the situation to the best scientists from different countries, with the support of the United Nations developed the Kyoto Protocol [5].

The Kyoto Protocol, signed in 1997, provides for a sharp reduction of greenhouse gases emissions into the atmosphere through the mechanism of international trade of quotas for the gases emissions. Under the protocol, industrialized countries obliged to reduce carbon dioxide emissions by $1-2 \%$. States and separate economic entities in their territories can buy and sell quotas for greenhouse gases emissions at the international, national or regional markets. Details of market regulation mechanism of quotas for greenhouse gases emissions are given in publication [6].

The main purpose of this article is to consider the relationship between various environmental issues, and on the basis of this analysis forecast tendencies of environmental issues development in general, and each issue separately. To do this, standard methods were used: the method of linear interpolation, calculation of Pearson correlation coefficients and Caterpillar SSA method. The attempts to study relationships of different subjects on the basis of the publications analysis were made in [7-10]. Thus, in publication [7] interdisciplinary relationships are studied. Influence of immigration after the collapse of the Soviet Union on the dynamics of scientific publications is studied in works [8-10]. The main content of this work is qualitative analysis, which is mainly of descriptive nature. In this work the authors tried to complement the study of this issue with mathematical methods.

\section{Results}

Data of publications on 6 environmental issues for the period 1980-2013 is given in Table №1. All the represented curves (Figure 1) are well approximated by the equation, which is a product of two functions: $y=f_{1}(x) \cdot f_{2}(x)$, where $f_{1}(x)$ is Verhulst equation and $f_{2}(x)$ is damped exponential curve. Function $f_{1}(x)$ characterizes "generation" of works on the selected subject, $f_{2}(x)$ - "oblivion" of a particular publication. Thus, the equation is as follows:

$$
y=\exp (-a x) \frac{K x_{0} \exp (r x)}{K+x_{0} \exp (r x)-x_{0}}
$$

where $K$ is the maximum amount of articles; $r$ - growth parameter; $x_{0}$ - number of articles 
at the initial time. Coefficients $K, r, x_{0}, a$, are respectively equal: $K_{2}=1164, r_{2}=0,003163$, $x_{02}=1, a_{2}=0,003163 ; K_{3}=2064, r_{3}=0,003448$, $x_{03}=1, a_{2}=0,003448 ; K_{4}=10670, r_{4}=0,002855$, $x_{04}=17, a_{4}=0,004264 ; K_{5}=39892, r_{5}=0,003383$, $x_{05}=22, a_{5}=0,004775 ; K_{6}=4402, r_{6}=0,002444$, $x_{06}=22, a_{6}=0,003825$. Approximation of the curves in Fig. 1, solution of Verhulst equation with delay is also possible:

$$
\begin{aligned}
& \frac{d y}{d x}=c_{1} y(x)-c_{2} y^{2}(x)+ \\
& +c_{3} y(x-\tau)-c_{4} y^{2}(x-\tau),
\end{aligned}
$$

where $\tau$ is delay time.

Let us analyze graphs in Fig. 1 in details.

All the curves, except curve 1 (Kyoto forest), demonstrate the same exponential nature of growth after 1993. The similar behavior of the curves is observed in 1984-1987, and the curves $\mathrm{CO}_{2}$ forest, Climate warming and Climate change have the common peaks in about 1987, and the curves $\mathrm{CO}_{2}$ forest and Climate warming have the common minimums in 1988 respectively. The local minimum of Climate warming curve in 1983 coincides with a local maximum of Green house effect curve. Thus, during the period 19801990s the interest to these environmental issues remained practically constant.

Synchronous maximums of 1992 are observed in almost all the curves, what is explained by holding the famous conference in Rio de Janeiro.

Further, we see a slight decline of the interest to environmental issues in the period of 1993-1995. Starting from 1997 an increase of publications is observed again.

Analysis of the data graphs with accumulation (Fig. 2-3) demonstrates a tendency of increase in the number of publications in the future for all environmental issues, with the exception of Kyoto forest, for which there is a tendency of decline.
It can be seen (Fig. 3) that the topics of Climate warming, Climate change and Greenhouse effect are developing simultaneously throughout the time period. Starting from 1992, synchronism, as mentioned above, is presented in the development of all these topics.

Against this background, Kyoto forest, where minimums in 1992 and 1995-1997 and maximums in 1991, 1993-1994 respectively are observed stands out. These minimums coincide with holding of the global environmental congresses of 1992 and 1997.

In Fig. 3 two groups with the same dynamics of development are clearly distinguished. These are Carbon forest, Climate warming, Climate change and $\mathrm{CO} 2$ forest and Greenhouse effect groups. For the first group it is possible to forecast a sharp increase in the number of publications in the future. The similar forecast can be made for the second group; however, the rate of growth in the number of publications will be slightly slower in comparison with the first group. For Kyoto forest, as mentioned above, on the contrary, a sharp decline of publications is predicted in the future.

Let us consider the graph of derivative $\frac{d y}{d t}$ alteration over time (Fig. 4). Synchronous maximums of 1992 are observed in almost all the curves, what is explained by holding the famous conference in Rio de Janeiro. In Fig. 4 this process is displayed by the presence of the derivative extremums on the curves. Fig. 4 confirms that approximately from 1980 to 1990 the interest to all environmental issues remained constant.

Derivative maximums, falling on the period of 1992 coincide in almost all the curves.

The next major maximums account for 1997. The presence of this maximum coincides with the emergence of the Kyoto Protocol.

From 2000-2004, the interest to the problems of climate change, $\mathrm{CO}_{2}$ emissions and 
Table 1. Environmental Publications for the Period of 1980-2013

\begin{tabular}{|c|c|c|c|c|c|c|}
\hline 1980 & 0 & 0 & 1 & 17 & 22 & 16 \\
\hline 1981 & 0 & 0 & 1 & 11 & 25 & 18 \\
\hline 1982 & 0 & 0 & 0 & 15 & 26 & 26 \\
\hline 1983 & 0 & 0 & 0 & 16 & 36 & 29 \\
\hline 1984 & 0 & 0 & 1 & 9 & 35 & 37 \\
\hline 1985 & 0 & 0 & 3 & 15 & 17 & 21 \\
\hline 1986 & 0 & 0 & 8 & 27 & 40 & 19 \\
\hline 1987 & 0 & 0 & 4 & 21 & 51 & 37 \\
\hline 1988 & 0 & 0 & 2 & 44 & 66 & 44 \\
\hline 1989 & 0 & 0 & 7 & 50 & 131 & 50 \\
\hline 1990 & 0 & 0 & 18 & 90 & 287 & 90 \\
\hline 1991 & 4 & 1 & 102 & 312 & 860 & 312 \\
\hline 1992 & 1 & 5 & 153 & 319 & 1012 & 319 \\
\hline 1993 & 6 & 18 & 157 & 330 & 1146 & 330 \\
\hline 1994 & 6 & 11 & 156 & 364 & 1257 & 481 \\
\hline 1995 & 2 & 32 & 238 & 518 & 1661 & 551 \\
\hline 1996 & 2 & 34 & 271 & 553 & 1840 & 626 \\
\hline 1997 & 2 & 39 & 270 & 635 & 2232 & 687 \\
\hline 1998 & 9 & 37 & 300 & 696 & 2432 & 707 \\
\hline 1999 & 23 & 43 & 345 & 759 & 2636 & 661 \\
\hline 2000 & 28 & 64 & 361 & 848 & 2932 & 693 \\
\hline 2001 & 30 & 76 & 410 & 960 & 3245 & 780 \\
\hline 2002 & 40 & 125 & 440 & 1041 & 3551 & 879 \\
\hline 2003 & 35 & 135 & 470 & 1181 & 4084 & 967 \\
\hline 2004 & 48 & 174 & 508 & 1321 & 4490 & 976 \\
\hline 2005 & 36 & 152 & 579 & 1476 & 5165 & 1074 \\
\hline 2006 & 45 & 202 & 602 & 1611 & 5941 & 1214 \\
\hline 2007 & 53 & 235 & 592 & 1979 & 7532 & 1317 \\
\hline 2008 & 53 & 280 & 610 & 2431 & 9240 & 1474 \\
\hline 2009 & 53 & 335 & 599 & 2924 & 11353 & 1744 \\
\hline 2010 & 64 & 372 & 679 & 3190 & 13117 & 1723 \\
\hline 2011 & 58 & 446 & 732 & 4032 & 15565 & 2131 \\
\hline 2012 & 58 & 512 & 938 & 4527 & 17316 & 2273 \\
\hline 2013 & 35 & 582 & 1032 & 5335 & 19946 & 2201 \\
\hline
\end{tabular}

global warming remains practically constant, since the rate of increase in the number of publications on these topics is close to zero. Relatively large synchronous maximums are observed for Kyoto forest, Carbon forest and Greenhouse effect in 2003. There is a small maximum for $\mathrm{CO}_{2}$ forest in 2004. On the contrary, synchronous minimums correspond to the topics of Kyoto forest, Carbon forest and Greenhouse effect in that year. Since 2004, interest in climate change has sharply increased as well, which is reflected by exponential growth of the curve for the period of 20042010 in the graph. There is the same tendency 


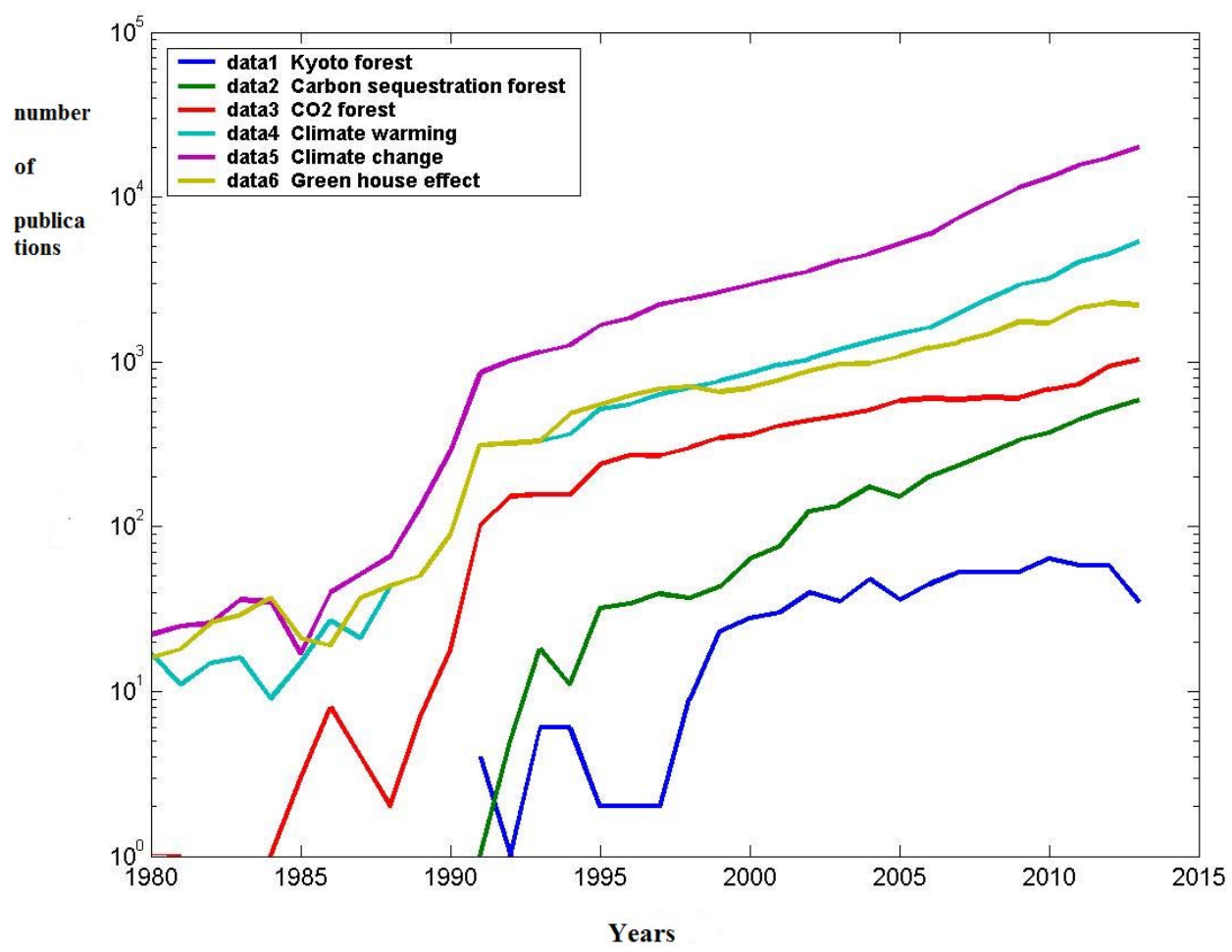

Fig. 1. Publications for the Period of 1980-2013

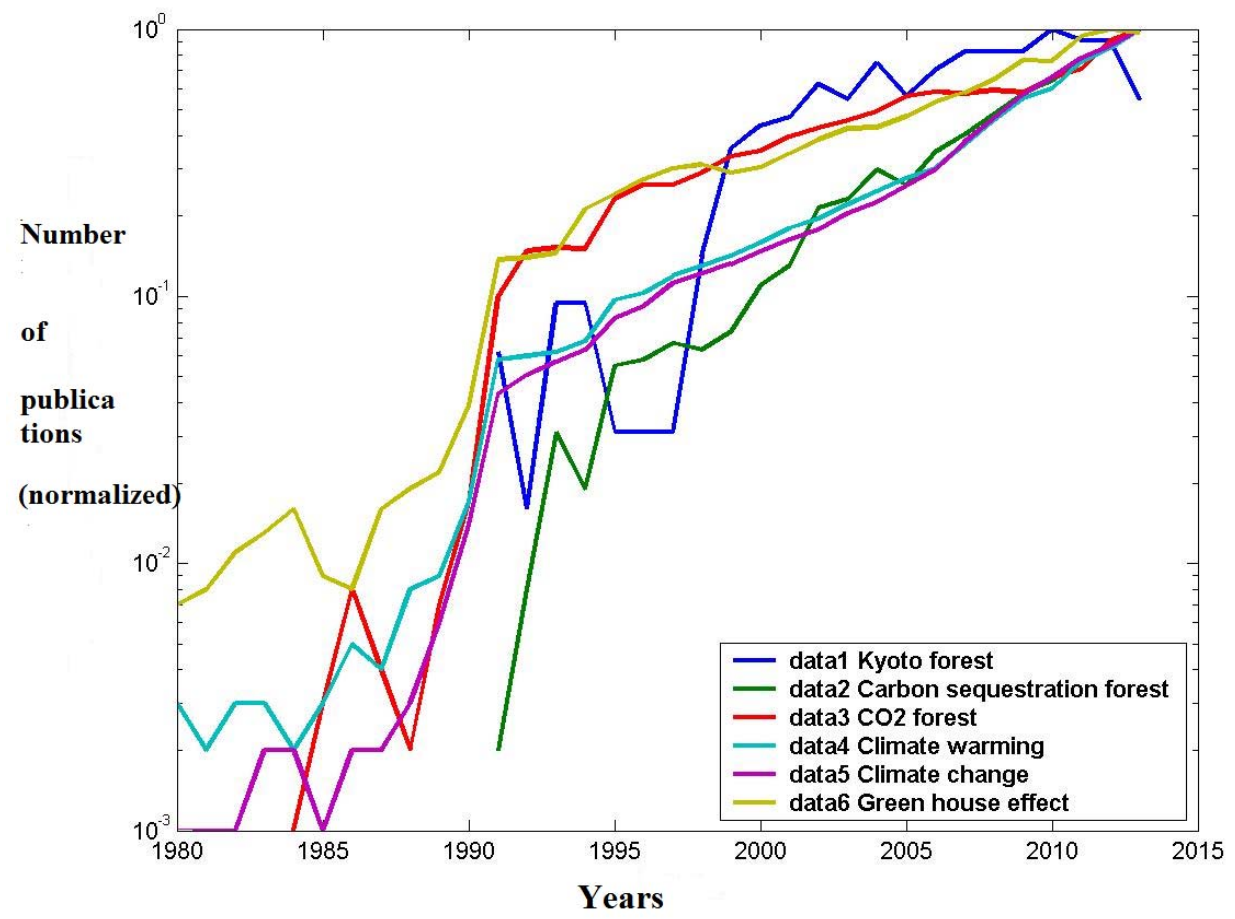

Fig. 2. Publications for the period of 1980-2013 (normalized graph with accumulations). 


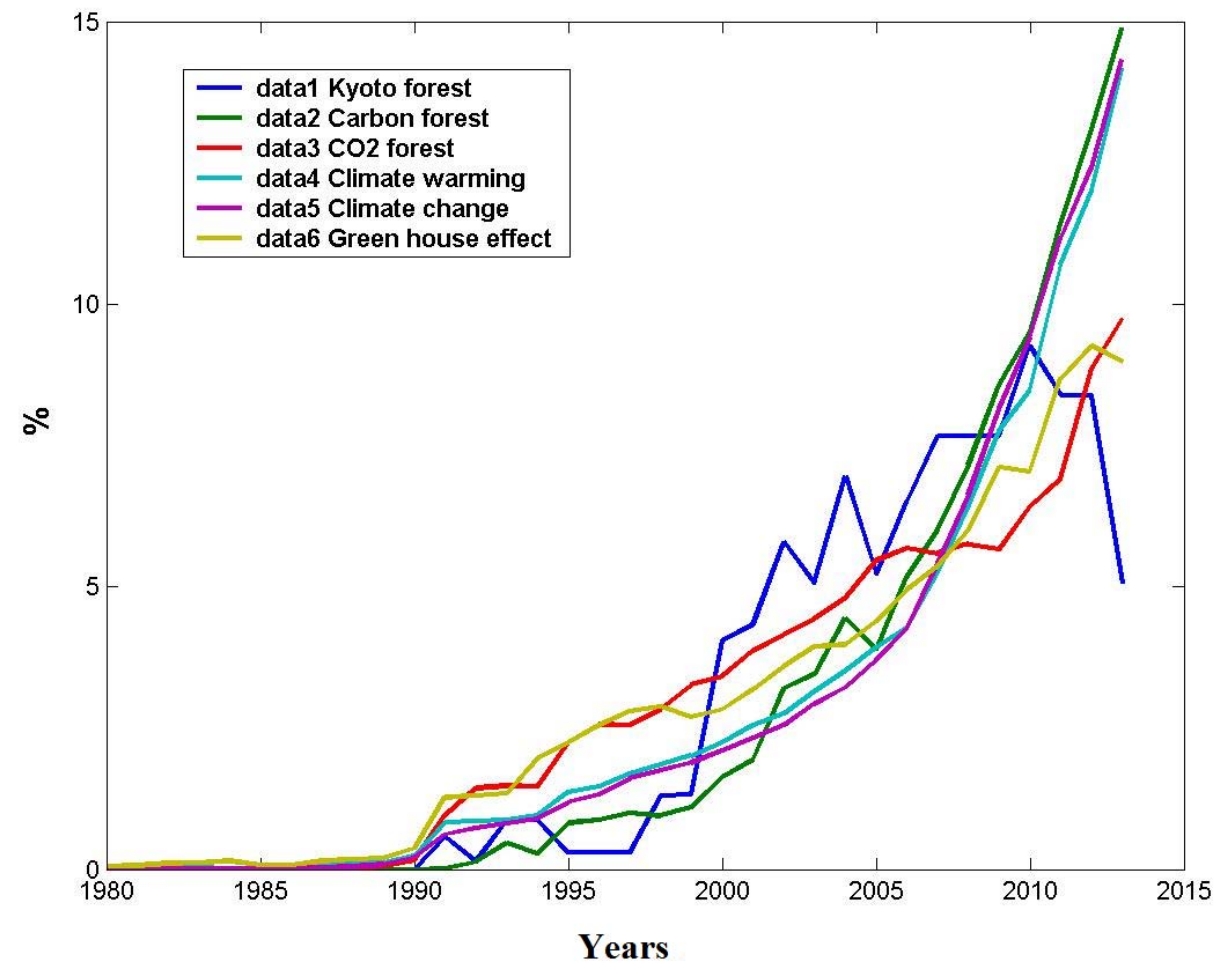

Fig. 3. Publications for the Period of 1980-2013 (graph with accumulations in percentage)
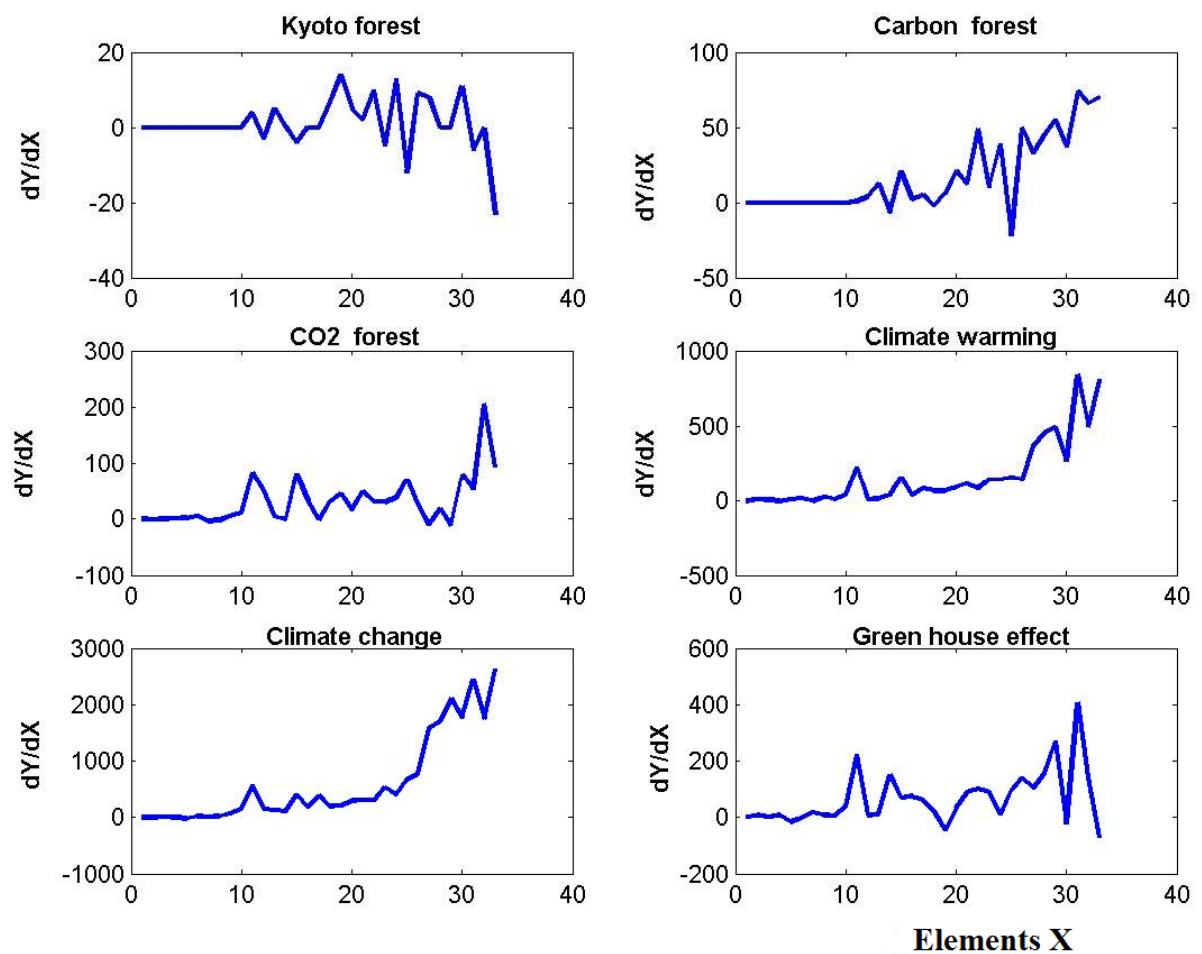

Fig. 4. Dynamics of the Number of Publications 
for Greenhouse effect, where a sharp decline (minimum) is observed in 2010.

The following synchronous minimums fall on 2011, they are observed in all the curves except Carbon forest. A brief analysis of dynamics of the publications rate of change shows synchronous change of growth rate in the number of publications due to the external factors influence. Calculation of Pearson correlation coefficient shows a very close correlation of the environmental issues data $k_{12}\left(y_{1}, y_{2}\right)=0,84$, $k_{13}\left(y_{1}, y_{3}\right)=0,89, k_{14}\left(y_{1}, y_{4}\right)=0,82, k_{15}\left(y_{1}, y_{5}\right)=0,82$, $k_{16}\left(y_{1}, y_{6}\right)=0,89, k_{23}\left(y_{2}, y_{3}\right)=0,99, k_{24}\left(y_{2}, y_{4}\right)=0,99$, $k_{25}\left(y_{2}, y_{5}\right)=0,99, k_{26}\left(y_{2}, y_{6}\right)=0,99, k_{34}\left(y_{3}, y_{4}\right)=0,94$, $k_{35}\left(y_{3}, y_{5}\right)=0,93, k_{36}\left(y_{3}, y_{6}\right)=0,98, k_{45}\left(y_{4}, y_{5}\right)=0,99$, $k_{46}\left(y_{4}, y_{6}\right)=0,97, k_{56}\left(y_{5}, y_{6}\right)=0,96$.

It especially concerns the issues of carbon dioxide absorption by forests $\left(\mathrm{CO}_{2}\right.$ forest), global warming (Climate warming), the issues of climate change (Climate change) and the greenhouse effect (Greenhouse effect).
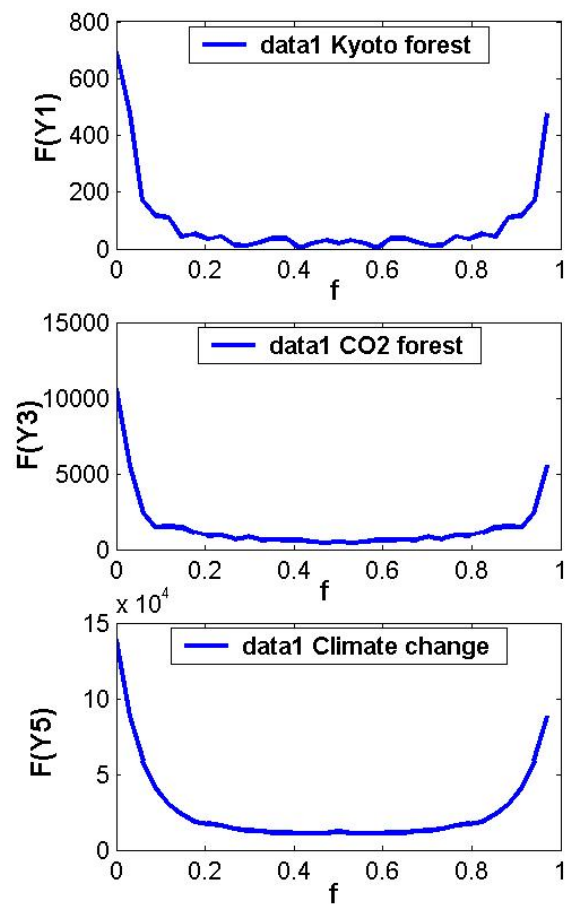

"Caterpillar method" will be used for a more in-depth analysis of various environmental issues. Caterpillar method consists in decomposition of the time series into simple components: periodic and oscillatory components, as well as noise components. The resulting decomposition serves as a basis for time series and its individual components forecasting. We decompose our time series into several components. In each "box" the largest value will be chosen, and each value will be numbered. Next, we will take the natural logarithm of each value and its number and make a graph of dependence of the highest value of the natural logarithm on the natural logarithm of the number. We will find slope coefficients of the lines obtained. The slope coefficients of the lines are respectively equal: $k_{1}=1,84, k_{2}=3, k_{3}=1,86$, $k_{4}=1,18, k_{5}=4,48, k_{6}=2,65$.

Analysis of the data obtained by the caterpillar SSA method evidences the presence of "grey noise" (Fig. 5), which can be interpreted as the presence of
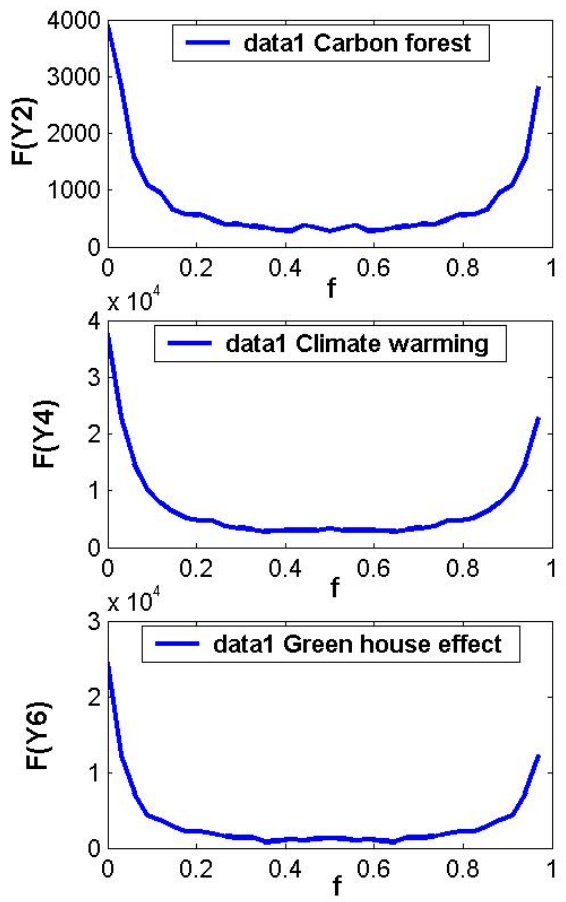

Fig. 5. The Fourier Transform 
an initial surge of interest in this topic, after which a "constant rate" of scientific community's attention is established. This fact once again indicates of the decisive effect of external factors.

\section{Resume}

Change in the number of publications over $y=\exp (-a x) \frac{K x_{0} \exp (r x)}{K+x_{0} \exp (r x)-x_{0}}$, time is well approximated by the function: which means that initial period of a scientific issue development is characterized by active "extension" of the number of publication, followed by a period of neglect.
Analysis of the dynamics of change in the speed of publication on the selected six environmental issues reflects the important role of an initial external factor, after which influence, a certain "natural frequency" of public interest is established for each issue.

Maximums and minimums of the rate of change in the number of publications for all the curves coincide with important social events such as major conferences on environmental issues of 1992 and 1997, which once again indicates of the crucial role of external factors.

\section{References}

Parry, Martin, Palutikof, Jean, Hanson, Clair and Lowe, Jason (2008). Squaring up to reality, In Nature (2), 68-69.

Electronic Data. Available at: http//www.zvezdi-oriona.ru/205008.htm.

Electronic Data. Available at: http://www.lse.ac.uk

Electronic Data. Available at: http:// www.albioncom.ru/univercity/england/catalog/?id=40

Electronic Data. Available at: http://unfccc.int/resource/docs/convkp/kprus.pdf

Maergoyz, L.S., Sidorova, T.Y., Khlebopros, R.G. (2011). Matematicheskii algoritm raspredeleniia vybrosov parnikovykh gazov [Mathematical Algorithm of Greenhouse Gases Emissions Distribution], In Sibirskii zhurnal industrial'noi matematiki [Siberian Journal of Industrial Mathematics], 14(2), $78-83$.

Wallace, M. L., Lariviere V., Gingras, Y. (2009). Modeling a Century of Citation Distributions, In J. Informetrics, 3, 296-303.

Borjas, G. J., Doran, K. B. (2012). The Collapse of the Soviet Union and the Productivity of American Mathematicians, In Quart. J. Econom., 127, 1143-1203.

Hunt, J., Gauthier-Loiselle, M. (2010). How Much Does Immigration Boost Innovation? In Am. Econom. J. - Macroecom., 2, 31-56.

Franzoni, C., Scellato, G., Stephan, P. (2014). The Mover's Advantage: The Superior Performance of Migrant Scientists, In Econom. Lett, 122, 89-93. 


\title{
Наукометрический анализ \\ динамики числа публикаций
}

по экологическим тематикам

\author{
А.В. Салагаева ${ }^{\mathrm{a}, \tilde{0}}$, C.В. Тазеев ${ }^{\mathrm{a}, \boldsymbol{0}}$, \\ В.Л. Гавриков ${ }^{\mathrm{a}}$ Р.Г. Хлебопроса ${ }^{\mathrm{a}, \boldsymbol{\sigma}}$ \\ ${ }^{a}$ Сибирский федеральный университет \\ Россия, 660041, Красноярск, пр. Свободный, 79 \\ ${ }^{\sigma}$ Президиум Красноярского научного иентра СО РАН \\ Россия, 660036, Красноярск, Академгородок, 50
}

В данной статье проведен наукометрический анализ данных числа публикаций по шести экологическим тематикам. Использовались следующие методы анализа: метод линейной интерполячии, метод ssa, корреляционный анализ.

Методом линейной интерполяции найдено аналитическое выражение для описания изменения числа публикаций со временем. Степень “зашумленности” данных проанализирована методом ssa.

Подробно проанализирована скорость изменения числа публикаций на заданном временном интервале. Показано существенное значение внешних факторов на первоначальное число и динамику роста публикаиий.

Ключевые слова: киотские леса, динамика публикаций, уравнение Ферхюльста, метод ssa.

Научная специальность: 08.00.00 - экономические науки. 